\title{
Unlashing the next wave of business models in the internet of things era: A systematic literature review and new perspectives for a research agenda
}

\author{
Mirheta Omerovic \\ Technische Universität Darmstadt \\ Germany \\ omerovic@is.tu-darmstadt.de
}

\author{
Nihal Islam \\ Technische Universität Darmstadt \\ Germany \\ islam@is.tu-darmstadt.de
}

\author{
Peter Buxmann \\ Technische Universität Darmstadt \\ Germany \\ buxmann@is.tu-darmstadt.de
}

\begin{abstract}
Pervasive digitization of products and services open additional avenues for the next wave of business model opportunities. Most of firms are aware of the monetization potentials that the Internet of Things (IoT) has to offer, however, they still struggle to create a compelling value propositions. Despite the attention of both research and practice onto business models and the IoT, only few concepts and research endeavors regarding their intersections exist. This paper tends to unleash the specificity of the business models within the IoT technologies, and motivate new, ecosystem, perspective for upcoming research. Following a rigorous methodology for a comprehensive and systematic literature review, we develop five literature clusters related to the Internet of Things-driven business model research, evaluate and analyze the papers within clusters, and finally identify the gaps and propose directions for future research.
\end{abstract}

\section{Introduction}

The Internet of Things (IoT) technologies tremendously affect business relationships and, consequently, business models (BM). Typical example is the story of the General Electrics (GE), which nowadays faces non-traditional competitors such as SAP or IBM. Using the IoT applications, these new competitors shift the value proposition from plain equipment to additional efficiencies and benefit through advanced analytics and data [34]. Nowadays, we see many automotive manufacturers transforming from the mere car producers into the holistic solution providers, enhancing their products with digital features and platforms. For instance, Mercedes Benz Vans opened up a project house "Future Transportation" that is focusing only onto the digitalization of services and products. Such applications and state-of-the-art possibilities promise to fuel business profits. According to the Internet of
Everything Index (IoE), businesses generate \$613 billion of additional profits annually because of connected devices [6]. Gubbi et al. [27] estimate that the number of those devices will reach 24 billion by 2020 which corresponds to recent forecasts that promise exceptional economic impact of IoT applications, namely a revenue of $\$ 11.1$ trillion per year in 2025 [26], [48]. However, these numbers might be overoptimistic as due to the complexity and heterogeneity of IoT, businesses are striving to consign proper BMs able to reflect the interconnected nature of those technologies [43]. The transformative power of IoT requires a complete mind-set shift regarding the value creation and capture, which poses significant challenges [85]. Such shifts and various obstacles are hindering IoT-driven BM realization. For instance, major technical challenges such as scalability, resource scarcity and security [1], [31], business development obstacles [85] or the inertia of incumbent firms [70]. On the other hand, IoT creates the foundation for design of new profitable BMs and value exchange mechanisms [22, 23], [62], [86], and not only it is able to reshape the BMs but entire industry boundaries [63]. Nevertheless, so far only a few conceptualizations of the IoT-driven BMs have been introduced [43], [69], [74] and the literature coverage is still largely technology focused [82]. There is a lack of common knowledge on what these models are and how they should be constructed [18], [43], and [74]. The knowledge emerges from diverse fields of research and there is no uniform understanding on how these models should be conceptualized, defined or adopted.

In order to provide a common ground and motivate new perspectives for future developments in practice and research, this paper studies the research question of what is the current literature on BMs in the field of the IoT technologies and what are the implications for future works. The scope is twofold: First, we strive to provide the comprehensive and up-to-date literature review of the existing research, contributing to the establishment of the common body of knowledge. This in return, is going to help further conceptualize BMs 
within the IoT environment [79]. Second, it relates future research directions to each of the streams, building the space to facilitate theory development and uncover areas where research is needed [83]. Additionally, from a practical perspective, this paper adds value to the businesses, notably to the incumbent firms, as the insights on the existing IoT-driven BM research lead to an improved understanding of this environment. Without a well-developed BM, any kind of organization is going to fail in delivering or capturing the value [70]. Moreover, this overview is of particular value for information systems (IS) practitioners who seek to design the information and communication tools supporting the business modeling processes (e.g. UML) [21]. In summary, the structured literature review as well as the outlook of the upcoming research in this paper tend to contribute to current debates and commence novel, intriguing discussions. This paper is structured as follows: first, we provide a brief theoretical background onto the development of BM concept, second we justify the systematic review methodology; and finally, cluster and discuss the corresponding literature streams of the IoT-driven BM research. Finally, we conclude with the outlook and directions for future research in BMs in the IoT era.

\section{Theoretical Background}

The existing diversity of BM definitions results in multiple annotations (see for example [13], [45], [70], [72], [79], etc.). However, many researchers agree that the BM helps interpret how a specific firm is conducting its business [12], [59], [71]. We argue, that the firm centric view has to be broaden, and merging two definitions introduced in Zott et al. [91], and Zott, and Amit [92], we define BM as the value creation tool that depicts the content, structure, and governance of transactions enabling a system of interdependent activities that transcends the focal firm and spans its boundaries. IoT technologies bundle applications spanning the boundaries of a firm and in nature represent the assemblage systems irreducible to its individual parts, therefore it is of crucial importance to include both firm and ecosystem perspective when analyzing the IoT-driven BMs [43], [55], [93].

Firm centric concept started to evolve within the widespread adoption of computer networks in the 1990s [20], [25], [28] [39], [45], [89], [91]. Through the years, the research focus shifted from the ebusinesses [2], [14], [72] to the BM research arising from multiple disciplines such as strategy, innovation, management, and IS [12], [40], and [58]. Mostly the research was generic [79], but certain scholars introduced domain-specific taxonomies of particular subtypes [29], [64], [68]. Additionally, some researcher identified and analyzed various components of the BMs [60], [67], while others used them to provide a method of BM discovery for technology entrepreneurs [51]. Some scholars claim that the recent research on clarifying the BM concept and its constitutive elements or components [28], [58] helped establish "an increasingly uniform understanding" of the BMs [81]. However, there are still dozens of academics who argue that the academic research on BM is still largely underdeveloped [91] and that narrow - firm centric approach is not suitable for new, highly interconnected environment. BMs based on today's largely static information architectures and firm-centric nature face challenges as new methods of creating value arise (e.g., specific location, dynamic pricing, usage fees) [15]. The literature on business ecosystems highlights the need for a deeper network view on BMs [11], [52] as existing templates and frameworks might not be adequate tools when examining the interdependent nature of the growth and success of companies evolving within the same ecosystem [88]. Considering the development of the IoT field, it is evident that interdependency of different actors through technical and business ties is becoming essential [86]. However, despite being around for already two decades and touching upon every sphere of our lives [82], there remains substantial discrepancy regarding the IoT concept and its understanding. It was firstly presented in 1998, focusing on social community and industries [63], still there is no commonly accepted definition and we rather use it as an expression to describe the concept of connecting objects for various purposes including identification, communication, sensing, and data collection across the Internet [82]. From a technical perspective, the IoT applications serve as enablers of physical objects to transform analog information into digital [90]. We reaffirm the definition introduced in Haller et al. [31] who consider the IoT as a world where physical objects seamlessly integrate into the information network and can become active participants in business processes. Such utilization of the IoT technologies introduces new business opportunities as remarkable improvements in the IoT sensor and actuator technologies and decrease in costs allow companies to leverage new data insights, introduce advanced offerings [86], and create completely new IoT enabled BMs [62]. For instance, consumer data might allow for both personalization and standardization of the offerings, resulting in new profit opportunities [55]. In other words, digitally enhanced products will allow companies to offer entirely new solutions, enhance value propositions, or target new customer segments [23]. For successful nutrition of such immense opportunities, there is a necessity for development of dedicated BM conceptualizations, frameworks, tools and methods. Given the disruptive nature of the IoT [30], current general approaches should be altogether reinvented to fit the dynamic and flexible nature of the IoT environment [77]. 


\section{Process of Systematic Review}

To answer our research question of what is the current study on BMs in the field of IoT technologies and what are the implications for future research, we conduct a systematic literature review (SLR). In order to identify key scientific contributions about the IoTdriven BMs, we follow a rigorous protocol, consisting of a replicable, scientific and transparent process introduced in Tranfield et al. [71]. This is a highly cited and one of the standard reference for the SLR method in IS. The SLR allows us to synthesize past knowledge about the research topic, identify important biases and knowledge gaps in the literature, and finally propose future research directions [53]. By applying this method, we are able to identify the gap between diversified research on IoT-driven BM literature.

The following detailed description of the method and analysis process supports the reproducibility of our research [46]. In our first phase, we conducted the interviews with four experts in the IoT-field from two leading European manufacturers dedicated to the digitalization transformation and parallel we initially screened the relevant literature. This procedure leads us into a second one where we determined the relevant terms for our literature search. We found out that the following terms known so far from the research field are still relevant for our literature search: IoT Business Model, and Internet of Things AND Business Model. These search terms were used to query the titles, abstracts and keywords of the various publications. We used INFORMS and ACM databases that cover the Association for IS journals and the top 50 leading IS journals [80]. Additionally, we considered three leading practitioner-oriented journals, namely the California Management Review, Harvard Business Review, and MIT Sloan Management Review as this adds practical value to our paper and allows broader perspective onto the research paradigm [91]. The initial list consisted highly ranked 120 publications in all sources until late 2018. After reading through the abstracts and conclusions, we filtered the publications based on topic relevance. Out of this process, 80 papers are selected for focus analysis. Within focus analysis, we read the papers, and based on first topic and then journal relevance, we selected 20 publications. Backward and forward search led us to additional six papers. As a result, the final list including the journal publications, conference proceedings, completed and research papers, consisted of 25 publications. The process of publications extraction is illustrated in Figure 1. To extract the comprehensive clusters of the literature streams on IoT-driven BMs research $(n=25)$, we follow the inductive approach introduced in Miles et al. [50] and using the MAXQDA software for coding the literature material.

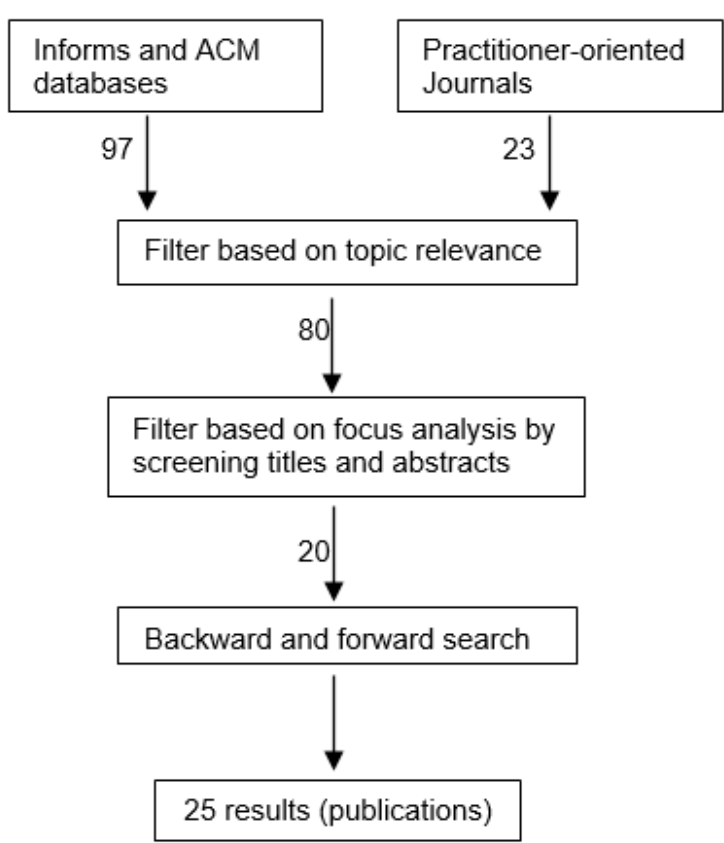

Figure 1. Publications extraction process

Inductive approach allows us to search for patterns (clusters) from observations and the development of theories. It consisted of two coding cycles. Firstly, we formed categories for each literature stream on IoTdriven BMs. For this, we followed the definitions and descriptions of the BMs literature research subdomains presented in Pateli and Giaglis [60]. Using the five expert judgments and reliability testing, they proposed following eight sub-domains: Definitions, components, taxonomies, conceptual models, design methods and tools, adoption factors, evaluation models, and change methodologies [60]. Accepting these domains as "a validated instrument that classifies BM research" [60], we adopted the definitions of existing categories as a reference point. The analysis of the literature on the IoT-driven BMs followed the benchmarking process, where each selected publication was tested against all existing sub-domains. The authors conducted this process individually, merged the outcomes and finally consolidated the results. In a second cycle, we involved three additional experts dedicated to the research on business models and IoT to critically revise the clustering process and according to abstracts assign the papers to particular sub-domain. In this process, we arrived to the consensus where five out of eight existing sub-domains appeared to satisfy the criterion developed in Pateli and Giaglis [60]. We structured the various volume of information by aggregating the codes into five main categories:

1. Conceptualization refers to the group of literature dedicated to present viable IoT-driven BM frameworks or patterns, 
2. Components identifies the group of literature concerned with analyzing the decomposed constructs of the IoT-driven BM concept,

3. Design Methods \& Tools concerns the development and use of IoT-driven BM modelling tools used to automate and leverage the process of design,

4. Taxonomies relates to possible categorizations of IoT-driven BMs into a number of typologies based on various criteria and,

5. Adoption Factors refers to the stream analyzing challenges that affect the organizational adoption of IoT-driven BMs.

Lastly, in a third phase as described in Tranfield et al. [71], we identified the research gaps in each subdomain and proposed directions for future research (see chapter 4).

\section{Literature Analysis of IoT driven business models}

This section presents an overview of existing research on BMs within the IoT technologies, extracted from 25 publications identified through the process of SLR. The publications are organized into five subdomains of the research framework introduced in Pateli and Giaglis [60]: Conceptualization, components, methods and tools, taxonomies and adoption factors.

Table 1 represents an overview of the findings, relating the authors to the sub-domains. Black color represents the domain that is profoundly analyzed, gray color is for limited analysis and white boxes mean that there is no analysis of those domains (see legend for analysis). In following sub-chapters, we aim to discuss the existing knowledge and establish an anatomy of diverse findings. We identify challenges for future research, and particularly motivate research that is going to lead the transformation of BMs rather than merely reflect or describe the existing cases.

\subsection{Conceptualization}

The cluster conceptualization refers to the literature dedicated to present IoT-driven BM frameworks or patterns. Research in this domain aims at organizing information about the relationships between various BM components from numerous perspectives [60].

In the literature on IoT-driven BMs, we identified couple of distinct streams. First, there is a research that target to capture the value interactions within the IoT.

Iivari et al. [35], for instance, proposed a framework for understanding the dynamics of value co-creation and co-capture in the context of Industrial Internet. Using two dimensions, stage- and scope \& scale of value co-creation and co-capture, they identified the corresponding BM type and introduced the so-called "oblique" model that incorporate simultaneously value co-creation and co-capture within the IoT ecosystem.
Table 1. Literature review

\begin{tabular}{|c|c|c|c|c|c|}
\hline $\begin{array}{l}\text { Author/s (Publication } \\
\text { Year) }\end{array}$ & 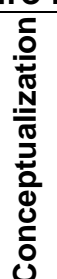 & 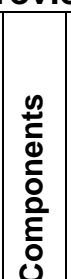 & 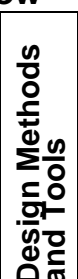 & 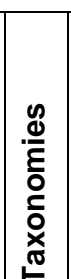 & 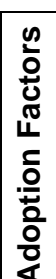 \\
\hline $\begin{array}{l}\text { Bucherer and Uckelmann } \\
\text { (2011) }\end{array}$ & & & & & \\
\hline Turber et al. (2014) & & & & & \\
\hline Sun et al. (2012) & & & & & \\
\hline Schladofsky et al. (2017) & & & & & \\
\hline livari et al. (2016) & & & & & \\
\hline Li and $\mathrm{Xu}(2013)$ & & & & & \\
\hline Ehret and Wirtz (2017) & & & & & \\
\hline Leminen et al. (2012) & & & & & \\
\hline Ju et al. (2016) & & & & & \\
\hline Dijkman et al. (2016) & & & & & \\
\hline Bock and Wiener (2017) & & & & & \\
\hline $\begin{array}{l}\text { Brynjolfsson and Saunders } \\
(2009)\end{array}$ & & & & & \\
\hline Mejtoft (2011) & & & & & \\
\hline Weinberger et al. (2016) & & & & & \\
\hline Chan (2015) & & & & & \\
\hline Chui et al. (2010) & & & & & \\
\hline Teece (2010) & & & & & \\
\hline Fleisch et al. (2015) & & & & & \\
\hline $\begin{array}{l}\text { Vermesan and Friess } \\
(2016)\end{array}$ & & & & & \\
\hline Westerlund et al. (2014) & & & & & \\
\hline Wurster (2014) & & & & & \\
\hline $\begin{array}{l}\text { Bilgeri and Wortmann } \\
(2017)\end{array}$ & & & & & \\
\hline Haller et al. (2009) & & & & & \\
\hline Klein et al. (2017) & & & & & \\
\hline Saarikko et al.(2017) & & & & & \\
\hline Onar et al. (2017) & & & & & \\
\hline
\end{tabular}

Legend for analysis: $\square$ in-depth $\square$ limited $\square$ none

Similarly, Weinberger et al. [86] built the concept based on value components: exchanges, extract (monetized part of the ecosystem), and design. Vermesan et al. [77] explored eight different layers to classify the value creation in IoT and identify the participating stakeholders. For each layer, they proposed the corresponding type of BM as the most commonly ones used across the markets. Secondly, there are scholars who mostly focus on specific characteristics of the IoT technologies. Hognelid and Kalling [30] provided a concept built upon three constructs, transaction structure, content, and governance. For each construct they assigned four different capabilities of the smart and connected products, monitoring, control, optimization and autonomy. Schladofsky et al. [66] introduced the framework considering the heterogeneity of smart node 
devices at the edge, network technologies, multiple standardization initiatives, the immaturity of innovation, and the unstructured ecosystems. Finally, Ehret and Wirtz [19] built the Industrial IoT-driven BM clusters based on the concept of non-ownership contracts. They introduced three possible BMs for the IoT environment within the manufacturing industry. Finally, there are scholars who design conceptual models assuming the ecosystem perspective as the defining scheme. For instance, Leminen et al. [43], using the ecosystem and customer dimensions, identified four IoT-driven BM types. Turber et al. [74] set forth the "Framework for IoT BMs". Based on the service-dominant logic [76] and using the design science approach [61], they formed the IoT-driven BM framework encompassing three dimensions identifying stakeholders, benefits of participation, and sources of value co-creation. Likewise, Sun et al. [69] introduced a so-called DNA model addressing three "How", "What" and "Why" elements of the IoT-driven BMs. Using the three blocks, design, needs, aspirations and smart logistics as the use-case, they demonstrated the cause-and-effect of existing relationships.

According to the raised analysis, we remark that there is a strong emphasis on different dimensions of the IoT-driven BMs, but the actors and mutual dynamic interactions are poorly examined. For instance, Vermesan et al. [77] affirm that the stakeholders involved in the IoT businesses might be participants in more than one layer; however, they do not describe the existing relationships nor the overlaps between different layers. In addition, many of the conceptualizations apply the firm-centric parameters onto different ecosystem IoT players. We urge for further developments of ideas onto how to derive a contemporary concepts that do merge all existing actors and their respective relationships. Specifically, we urge to direct the research into discovering the mutual relationships of various stakeholders included in the IoT ecosystem and dynamic exchanges.

\subsection{Components}

This sub-domain in Pateli and Giaglis [60] represents the cluster of the literature streams aimed at analyzing decomposed BM components and their fundamental constructs. Here, we identified the group of literature concerned with analyzing construct elements of the IoT-driven BM concept. In literature on BMs, the most commonly analyzed components are customer segments, value propositions, channels, customer relationships, revenue streams, key resources, key activities, key partnerships, and cost structure [58]. When it comes to the IoT-driven BM literature, the analysis of the components has been quite niche. Many scholars examined the value component as the crucial profit driver. However, there is a divergence in perceiving the importance of different value components. On one hand, Bucherer and Uckelmann
[7] stressed that the information and its exchange play a crucial role in the IoT network. Similarly, Bock and Wiener [9] evaluated customer data as the main IoTdriven BM value ingredient. On the other hand, Brynjolfsson and Saunders [10] profoundly described digital infrastructure as the core component. They claimed that digital infrastructures should be focused on as they are extremely scalable and can be upgraded or replaced with relative ease and at low costs. There are also scholars who pursued rather comprehensive analysis of value creation without weighting on particular propositions. For instance, Mejtoft [49] analyzed the value component from (i) manufacturing, (ii) supporting, (iii) and co-creative behavior of things perspectives. The manufacturing layer denoted the hardware aspect of the IoT, the supporting layer reflected the process of data collection for further value creation, and the co-creative layer uses IoT as a cocreative partner. In similar manner, Onar et al. [56] evaluated value proposition with respect to novelty, efficiency, lock-in power and complementarity parameters. Revising the previous IoT-driven BM Components cluster, one might conclude that the current research is value focused and quite few. In line with the findings in Dijkman et al. [18] in which the value proposition appears as the most significant building block of the IoT-driven BMs, these research efforts are highly advantageous for further studies. On the other hand, the analysis of other components, such us infrastructure and data ingredients is conducted rather marginally without emphasis. Additionally, there is virtually no targeted analysis of other important components such as customer relationships and key partners [18]. Due to this heterogeneity of research, we encourage further studies and empirical validations of the various IoT-driven BM components (e.g. how dimension of value exchange) and recommend particular attention to be given to "data" as one of the crucial drivers of future businesses.

\subsection{Methods and Tools}

In this sub-domain Pateli and Giaglis [60] include research that refers to tools used to leverage the process of designing a BM. This cluster concerns the development and use of mechanisms used to describe the process and eventually the components of designing the IoT-driven BM. In our analysis of the IoT-driven BM literature, we found couple of practically viable solutions for businesses. Chui et al. [15] introduced the tool with which they tend to answer the question of "How" for the process of the IoT business development. In other words, they aim to describe the most important actors and factors of the model development, building upon the framework introduced in Höller et al. [32]. Dijkman et al. [18] introduced components for BM for IoT applications based on BM Canvas (BMC) [59]. For instance, key partners included various types such as hardware Page 4573 
producers, software developers, data interpreters, launching customers, etc. In similar fashion and also using the BMC, Ju et al. [37] introduced the generic IoT-driven BM framework that consists of nine building blocks and elements in each block. Some of the building blocks reaffirmed findings in Dijkman et al. [18], while in some blocks, based on the interviews, they added or removed particular elements. Finally, Chan [16] introduced the tool that facilitates the visualization and arrangement of different IoT-driven BM components.

Despite many scholars calling upon the ecosystem perspective when designing tools for the IoT-driven BMs, most of the current research simply applies the existing method considering several different stakeholders. We argue that the future research has to embrace the ecosystem perspective when building or evaluating the specific BM design tools and methods for the IoT environment.

\subsection{Taxonomies}

This cluster in Pateli and Giaglis [60] relates to the possible categorizations of BMs into numerous typologies based on different criteria. They argue that in the field of e-BMs, there has been a relatively significant portion of work related to the derivation of a list of generic BM types. In the IoT context, there have been several efforts to cluster different BMs with respect to various criteria. Teece [70], for instance, demonstrated different BM configurations that the IoT businesses could adapt. One of the possible options he proposed is the 'razor/razor blade model', which involves pricing the razors (IoT hardware) inexpensively but aggressively marking up the blades (e.g. data). Fleisch et al. [23] used the 55 BM patterns introduced in Gassmann et al. [24] to test the IoT application onto the existing patterns. This iterative process lead them to introduce two additional models: (i) Digitally Charged Products that refers to the new possibilities of the digital transformation for manufacturing industries, and (ii) Sensor as a Service that embraces the idea of collecting, processing, and selling the data. Vermesan et al. [77] also used the BM Navigator [24] to propose different IoT-driven BM combinations that the most successful IoT companies are nowadays pursuing for their businesses. For instance, the "Amazon Combination" comprises affiliation, cash machine, e-commerce, leverage customer data, long tail, make more of it, user designed, and two-sided market BM options.

This fairly limited number of taxonomies indicates the need to further research and proper classify different types of the IoT-driven BMs. In line with the e-BM analysis [60], there is an underlying need for a holistic parameter for the development of the IoT-driven BM taxonomy. Therefore, we urge for further studies on the classification criteria for a proper development of the IoT-driven BM taxonomy.

\subsection{Adoption Factors}

Pateli and Giaglis [60] argue that the motivation behind research on key factors that might affect BM adoption has been to contribute, identify, and assess promising BMs under different organizational contexts. In our analyzing process, we identified eight papers striving to analyze the challenges or opportunities that affect the organizational adoption of the IoT technologies within the new BMs.

Firstly, there are scholars who argue that the IoT technologies are particularly forcing collaboration. For instance, Vermesan and Friess [78] claim that the IoT is forcing the movement from vertical to multi-purpose and collaborative solutions. Similarly, Loebbecke and Picot [43] affirmed that the IoT-driven BM challenges are particularly significant as organizations convert from industry-specific vertical IoT applications to horizontal ones spanning multiple industries. Secondly, there is a certain stream of literature focusing on crucial challenges specific for the IoT-driven BM introduction. Namely, Westerlund et al. [85] proposed three major obstacles of the IoT, namely (i) diversity of objects, (ii) immaturity of innovation, and (iii) unstructured ecosystems. Vargo and Lusch [76] extended this study, additionally introducing (i) the heterogeneity of network technologies, and (ii) multiple standardization initiatives. Supporting Westerlund et al. [85], they underlined the need to understand integrated value drivers (i.e., shared overall value for an entire IoT ecosystem) instead of fragmented ones (i.e., individual actors' value from specific applications or services) and suggested shifting the focus on value creation and value capture in BMs from the company level to the ecosystem one.

On the other hand, some scholars focused on particular business or technical obstacles such as Wurster [88] and Haller et al. [31]. Wurster [88] described (i) identification of horizontal needs and opportunities, (ii) internal team alignment, and (iii) overcoming the market maturity problem for IoT technologies, while Haller et al. [31] grouped technical issues into four clusters: internet scalability, identification and addressing, heterogeneity, and service paradigms. Saariko et al. [65] raised a number of fundamental issues related to the development of IoT-driven BMs including partnership strategy, data ownership, and technology diffusion. In particular, they posed several questions and draw upon the observations from the field to demonstrate that a financially sustainable solution needs to have the full support of all participants in order to enable the right preconditions for value creation. While Bilgeri et al. [5] provided the builder for developing BMs for IoT offerings; Bilgeri and Wortmann [4] identified sixteen barriers challenging that process. They structured them along four high-level innovation stages described in Luchs et al. [44]. 
Table 2. Research direction

\begin{tabular}{|l|l|}
\hline Concepts & $\begin{array}{l}\text { Rerivation of a contemporary loT- } \\
\text { driven BM concepts that merge all } \\
\text { existing actors and their respective } \\
\text { relationships; discovering the mutual } \\
\text { relationships of various stakeholders } \\
\text { included in the loT ecosystem and } \\
\text { dynamic exchanges. }\end{array}$ \\
\hline Components & $\begin{array}{l}\text { Further studies and empirical } \\
\text { validations of the various loT-driven } \\
\text { BM components (e.g. how dimension } \\
\text { of value exchange); particular } \\
\text { attention to be given to "data" as one } \\
\text { of the crucial drivers of future BM }\end{array}$ \\
\hline $\begin{array}{l}\text { Design } \\
\text { Methods } \\
\text { and Tools }\end{array}$ & $\begin{array}{l}\text { Embracement of the ecosystem } \\
\text { perspective when building or } \\
\text { evaluating the specific BM design } \\
\text { tools and methods for the loT } \\
\text { environment }\end{array}$ \\
\hline Taxonomies & $\begin{array}{l}\text { Need for a holistic parameter for the } \\
\text { development of the loT-driven BM } \\
\text { taxonomy; further studies on the } \\
\text { classification criteria for a proper } \\
\text { development of the taxonomy }\end{array}$ \\
\hline $\begin{array}{l}\text { Adoption } \\
\text { Factors }\end{array}$ & $\begin{array}{l}\text { Heading the future research towards } \\
\text { the analysis of the particular } \\
\text { obstacles related to the dimension } \\
\text { transformation (from vertical to } \\
\text { horizontal); the ecosystem dimension } \\
\text { of the loT-driven BMs and its defining } \\
\text { boundaries; test the adoption of the } \\
\text { loT-driven BMs within different } \\
\text { organization systems or structures }\end{array}$ \\
\hline
\end{tabular}

They argue that some of the resulting barriers appear to be fairly discussed in the BM Innovation literature, while others, which are particularly significant for the IoT environment, remain highly under researched.

Furthermore, we identified the scholars who tended to describe rather an impact of the IoT technologies onto the BMs such Chui et al. [15] who proposed six distinct types of emerging IoT applications and their respective usage. They distinguished between two broad categories: (i) information and analysis, and (ii) automation and control. Weinberger et al. [86] claimed that organizations can make use of the IoT in three different ways: 1) application of the IoT-generated data to improve the internal and external processes (highresolution management), 2) enrichment of the product portfolio with sensor and actuator technologies (digitally charged products), and 3) supply of the IoT technologies.

Analysis of the literature on IoT-driven BM challenges and opportunities reveals several gaps. To name a few, there are scholars who introduce the crucial issue of transformation from vertical to horizontal dimensions within the IoT introduction, but there are still no specificities on the nature of those challenges and their respective influence onto BMs. Therefore, we strongly recommend heading the future research towards the analysis of the particular obstacles related to this dimension transformation. Moreover, we see particular necessity to further discuss the ecosystem dimension of the IoT-driven BMs and its defining boundaries. Finally, there is still a need to test the adoption of the IoT-driven BMs within different organization systems or structures.

\section{Discussion of results}

IoT technology per se is unlikely to ensure a sustainable profitability if the corresponding BMs are not properly developed and adapted to its complex environment [68]. Some of the existing forms and tools might apply, but as the IoT has a disruptive nature [30] which can change the entire BM paradigm (e.g., ecosystem perspective); there is a need for a better understanding of the IoT influence on business development. Simply adding a few "digital features" to the theory could result in a trap of applying the known $\mathrm{BM}$ tools (e.g., BMC) to an environment that requires entirely new design rules. The analysis of the concepts related to the IoT-driven BMs reveals several good attempts to develop the theoretical frameworks (e.g. [43], [74]), however, the correlations and mutual dynamic interactions still have to be investigated. The utilization of the firm-centric parameters onto different ecosystem IoT players should be avoided in order to allow entirely new conceptualizations to emerge. The research onto the BM components has for long been neglected [81], and it is not surprising that there are only a few studies tackling components of the IoTdriven BMs. Particularly, some scholars researchers described and evaluated value components [7],[49], while others focused on specific elements such as infrastructure and data $[9,10]$. Taxonomy is at the starting point of development where we observe an application from the broad BM literature onto the IoT context. For instance, Fleisch et al. [23] and Vermesan et al. [75] both used the $55 \mathrm{BM}$ patterns introduced in Gassmann et al. [24] to introduce the BM taxonomies within the IoT environment. When it comes to the design methods and tools, there are couple of helpful and practical approaches introduced with focus on ideation and development of the IoT-driven BMs [5]. However, these do not include the relevant component descriptions and their respective roles. Finally, the adoption factors of the IoT-driven BMs group of studies seems to be extensively researched area compared to other domains.

Here, many scholars introduced different technical and technological challenges of adopting the IoT technologies (e.g., [77], [823]), while some of them tackled the obstacles of introducing BMs within the IoT [4]. It is also noticeable that many scholars argue for the significance of the ecosystem perspective when discussing the IoT-driven BMs. Originally presented by James F. Moore [36], the concept of business 
ecosystem stems from the insight that innovative businesses rely on various resources.

Horizontal movements of value creation and capture are ramifying BMs, and some scholars argue that the existing frameworks are unable to reflect the ecosystem complexity of the IoT environment [83]. Therefore, there is a necessity to account for the network and mutual dependence of different stakeholders.

We suggest two ways to advance the study of IoT BMs. First, tackling and addressing the research directions proposed in Table 2 will lead the research into the direction of the advanced body of knowledge that might provide the theoretical and practical relevance for many enterprises currently facing numerous obstacles in the process of IoT-driven BM adoption. Additionally, there is a necessity to comprehend the networked nature of the IoT and its surroundings [36], [42] as well as the significance of customer co-creation processes and challenges [17]. Second, as we are aware of the several limitations of this study, we suggest further analysis of the IoTdriven BM literature as well as the development of possible research questions. Without a doubt, the scholars should also tackle the so far non-identified clusters such as definitions for the IoT-driven BMs, evaluation models, and change methodologies.

\section{Conclusion}

Our results of literature review by clustering of existing IoT-driven BM research lead to the conclusion that this field seems to have potential for further research (see Table 2). The IoT technologies have the power to affect the entire overarching BMs [72], but only the enterprises able to overcome the challenges that this phenomenon poses will be able to benefit from the emerging opportunities [23]. Despite some scholars claim that the recent research on the BM concept helped establish "an increasingly uniform understanding" of the BMs [28], [58], [81]; we argue that narrow - firm centric approach is not suitable for new, highly interconnected environment. IoT-driven BMs should not base on largely static information architectures and firm-centric nature as the IoT field leads to high interdependency of different actors through technical and business ties [86].

This review has several limitations. First, much of the reviewed literature is quite recent and a few contributions have appeared in top journals. Second, although we followed "a validated instrument that classifies BM research" introduced in Pateli and Giaglis [60], our classification process still follows our understanding and perspective of "what makes sense". This method has been chiefly used in IS research, but for future research we strongly recommend following the rigorous taxonomy development method as for instance described in Nickerson et al. [54].

\section{References}

[1] Abdmeziem, M. R., Tandjaoui, D., \& Romdhani, I. (2016). Architecting the internet of things: state of the art. In Robots and Sensor Clouds (pp. 55-75). Springer, Cham.

[2] Applegate, L. M. (2001). E-business Models: Making sense of the Internet business landscape. Information technology and the future enterprise.

[3] Benkler, Y. (2006). The Wealth of Networks: How Social Production Transforms Markets and Freedom. Yale University Press, New Haven, CT.

[4] Bilgeri, D.; Wortmann, F. (2017). Barriers to IoT BM Innovation, in Leimeister, J.M.; Brenner, W. (Hrsg.): Proceedings der 13. Internationalen Tagung WI.

[5] Bilgeri, D., Brandt, V., Lang, M., Tesch, J., \& Weinberger, M. (2015). The IoT business model builder. A White Paper of the Bosch IoT Lab, Bosch Software Innovations $\mathrm{GmbH}$.

[6] Bradley, Joseph, et al. (2013) "Internet of Everything (IoE) Value Index: How Much Value Are Private-Sector Firms Capturing from IoE in 2013?" CISCO White Paper.

[7] Bucherer, E., Uckelmann, D. (2011). Business Models for the IoT. In: Architecting the IoT. Springer, Berlin.

[8] Bohn, J., Coroama, V., Langheinrich, M., Mattern, F., Rohs, M. (2005). Social, Economic, and Ethical Implications of Ambient Intelligence and Ubiquitous Computing. In: Weber, W., Rabaey, J., Aarts, E. (eds.) Ambient Intelligence, pp. 5-29. Springer, Heidelberg.

[9] Bock, M., \& Wiener, M. (2017). Towards a Taxonomy of Digital Business Models-Conceptual Dimensions and Empirical Illustrations. 38th International Conference on IS.

[10] Brynjolfsson, E., \& Saunders, A. (2009). Wired for innovation: how information technology is reshaping the economy. MIT Press.

[11] Carbone, P. (2009). The emerging promise of business ecosystems. Open Source Business Resource.

[12] Casadesus-Masanell, R., \& Ricart, J. E. (2010). From strategy to business models and onto tactics. Long range planning, 43(2-3), 195-215.

[13] Chesbrough, H., \& Rosenbloom, R. S. (2002). The role of the business model in capturing value from innovation: evidence from Xerox Corporation's technology spin-off companies. Industrial and corporate change, 11(3), 529-555.

[14] Cherian, E. (2001). Electronic business: the business model makes the difference. In Proceedings of the Eighth European Conference on IT Evaluation.

[15] Chui, M., Löffler, M., \& Roberts, R. (2010). The internet of things. McKinsey Quarterly.

[16] Chan, H. C. (2015). Internet of things business models. Journal of S.S. and Management.

[17] David Tilson, Kalle Lyytinen, Carsten Sørensen (2010). Research Commentary-Digital Infrastructures: The Missing IS Research Agenda. Information Systems Research 21(4).

[18] Dijkman, R. M., Sprenkels, B., Peeters, T., \& Janssen, A. (2015). Business models for the Internet of Things. International Journal of Information Management, 35(6).

[19] Ehret, M., \& Wirtz, J. (2017). Unlocking value from machines: business models and the industrial internet of things. Journal of Marketing Management, 33(1-2), 111-130. [20] El Sawy, O. A., \& Pereira, F. (2013). Digital business models: review and synthesis. In Business modelling in the dynamic digital space (pp. 13-20). Springer, Berlin.

[21] Eriksson, H. E., \& Penker, M. (2000). Business modeling with UML. New York, 1-12. 
[22] Engelbrecht, A., Gerlach, J., \& Widjaja, T. (2016). Understanding the anatomy of Data-driven business modelstowards an empirical taxonomy.

[23] Fleisch, E., Weinberger, M., \& Wortmann, F. (2015). Business models and the IoT. In Interoperability and OpenSource Solutions for the IoT Springer.

[24] Gassmann, O., Karolin F., and Michaela C. (2013). "The St. Gallen BM navigator.".

[25] Ghaziani, A., \& Ventresca, M. J. (2005). Keywords and cultural change: Frame analysis of business model public talk, 1975-2000. Kluwer Academic Publishers-Plenum.

[26] Greengard, S. (2015). The internet of things. MIT Press.

[27] Gubbi, J., Buyya, R., Marusic, S., \& Palaniswami, M. (2013). Internet of Things: A vision, architectural elements, and future directions. Future generation computer systems.

[28] Hedman, J., \& Kalling, T. (2003). The business model concept: theoretical underpinnings and empirical illustrations. European journal of information systems, 12(1). [29] Hartmann, P. M., Zaki, M., Feldmann, N., \& Neely, A. (2016). Capturing value from big data-a taxonomy of datadriven business models used by start-up firms. International Journal of Operations \& Production Management.

[30] Hognelid, P., \& Kalling, T. (2015). Internet of things and business models. In Standardization and Innovation in Information Technology (SIIT), 2015 IEEE.

[31] Haller, S., Karnouskos, S., Schroth, C. (2009). The Internet of Things in an Enterprise Context. In: Domingue, J., Fensel, D., Traverso, P. (eds.) Springer, Heidelberg.

[32] Höller, J., Boyle, D., Karnouskos, S., Avesand, S., Mulligan, C., \& Tsiatsis, V. (2014). From machine-tomachine to the internet of things. Cambridge: Academic P. [33] Hui, Gordon (2014). How the internet of things changes business models. HBR.

[34] Iansiti, M., and Lakhani, K. R. (2014). Digital ubiquity: How connections, sensors, and data are revolutionizing bus.

[35] Iivari, M. M., Ahokangas, P., Komi, M., Tihinen, M., \& Valtanen, K. (2016). Toward ecosystemic business models in the context of industrial internet. Journal of Business M.

[36] James, R. (2014). The internet of things: a study in hype, reality, disruption, and Growth. Raymond James US Research, Technology \& Communications, Industry Report. [37] Ju, Jaehyeon, Mi-Seon Kim, and Jae-Hyeon Ahn. (2016). Prototyping Business Models for IoT Service. Procedia Computer Science 91 (2016): 882-890.

[38] Klein, A., Fabiana B.P., and Rodrigo R.R. (2017). Internet of things-based products/services: Process and challenges on developing business models. Journal of Information Systems and Technology Management 14.3.

[39] Klang, D., Wallnöfer, M., \& Hacklin, F. (2014). The business model paradox: A systematic review and exploration of antecedents. International Journal of Management Reviews, 16(4).

[40] Lindgardt, Z., Reeves, M., Stalk, G., \& Deimler, M. S. (2009). Business model innovation. When the Game Gets Tough, Change the Game, The Boston Consulting Group.

[41] Li, H., \& Xu, Z. Z. (2013). Research on business model of Internet of Things based on MOP. In International Asia Conference on Industrial Engineering and Management Innovation (IEMI2012) Proceedings Springer, Berlin.

[42] Loebbecke, C., \& Picot, A. (2015). Reflections on societal and business model transformation arising from digitization and big data analytics: A research agenda. The Journal of Strategic IS.

[43] Leminen, S., Westerlund, M., Rajahonka, M., \& Siuruainen, R. (2012). Towards IOT ecosystems and business models. In Internet of things, smart spaces, and next generation networking (pp. 15-26). Springer, Berlin.

[44] Luchs, M. G., Swan, K. S., \& Creusen, M. E. (2015). Perspective: A review of marketing research on product design with directions for future research. Journal of PIM.

[45] Magretta, Joan (2002). Why business models matter.

[46] Mayring, P. (2014). Qualitative content analysis: theoretical foundation, basic procedures and software solution.

[47] Moore, J. F. (1993). Predators and prey: a new ecology of competition. HBR.

[48] Manyika, J., Chui, M., Bisson, P., Woetzel, J., Dobbs, R., Bughin, J., \& Aharon, D. (2015). Unlocking the Potential of the Internet of Things. McKinsey Global Institute.

[49] Mejtoft, T. (2011). Internet of Things and Co-creation of Value. In Internet of Things (iThings/CPSCom),4th International Conference on Cyber, Physical and Social Computing (pp. 672-677). IEEE.

[50] Miles, M. B., Huberman, A. M. and J. Saldana (2013). Qualitative Data Analysis. 3rd Edition. Sage.

[51] Muegge, S. (2012). Business model discovery by technology entrepreneurs. Technology Innovation Management Review, 2(4).

[52] Muegge, S. (2013). Platforms, communities, and business ecosystems: Lessons learned about technology entrepreneurship in an interconnected world.

[53] Mulrow, C. D. (1994). Systematic reviews: rationale for systematic reviews. Bmj, 309(6954).

[54] Nickerson, R. C., Varshney, U., \& Muntermann, J. (2013). A method for taxonomy development and its application in information systems. European Journal of IS.

[55] Ng, Irene CL, and Susan YL Wakenshaw. "The Internetof-Things: Review and research directions." International Journal of Research in Marketing 34.1 (2017): 3-21.

[56] Onar, Sezi Cevik, and Alp Ustundag (2018). "Smart and Connected Product Business Models." Industry 4.0: Managing The Digital Transformation. Springer, Cham.

[57] Oriwoh, E., Sant, P., \& Epiphaniou, G. (2013). Guidelines for Internet of Things Deployment Approaches The Thing Commandments. Procedia Computer Science.

[58] Osterwalder, A., Pigneur, Y., \& Tucci, C. L. (2005). Clarifying business models: Origins, present, and future of the concept. Communications of the association for IS.

[59] Osterwalder, A., \& Pigneur, Y. (2010). Business model generation: a handbook for visionaries, game changers, and challengers. John Wiley \& Sons.

[60] Pateli, A. G., \& Giaglis, G. M. (2004). A research framework for analysing eBusiness models. European journal of information systems, 13(4), 302-314.

[61] Peffers, K., Tuunanen, T., Rothenberger, M.A., Chatterjee, S. (2007): A Design Science Research Methodology for Information Systems Research. J. Manag. Inf. Syst. 24, 45-77.

[62] Porter, M. E., \& Heppelmann, J. E. (2014). How smart, connected products are transforming competition. Harvard business review, 92(11), 64-88.

[63] Qin, Y., Sheng, Q. Z., Falkner, N. J., Dustdar, S., Wang, H., \& Vasilakos, A. V. (2016). When things matter: A survey on data-centric internet of things. Journal of Network.

[64] Remane, G., Hanelt, A., Nickerson, R. C., \& Kolbe, L. M. (2017). Discovering digital business models in traditional industries. Journal of Business Strategy.

[65] Saarikko, T., Westergren, U. H., \& Blomquist, T. (2017). The Internet of Things: Are you ready for what's coming?. Business Horizons, 60(5), 667-676. 
[66] Schladofsky, W., Mitic, J., Megner, A. P., Simonato, C., Gioppo, L., Leonardos, D., \& Bröring, A. (2016). Business models for interoperable IoT ecosystems. In International Workshop on Interoperability and Open-Source Solutions (pp. 91-106). Springer, Cham.

[67] Shafer, S. M., Smith, H. J., \& Linder, J. C. (2005). The power of business models. BH.

[68] Schief, M., \& Buxmann, P. (2012). Business models in the software industry. In System Science (HICSS), 2012 45th Hawaii International Conference on (pp. 3328-3337). IEEE.

[69] Sun, Y., Yan, H., Lu, C., Bie, R. and Thomas, P. (2012) A Holistic Approach to Visualizing Business Models for the Internet of Things. Communications in Mobile Computing.

[70] Teece, David J. (2010): Business Models, Business Strategy and Innovation. In Long Range Planning 43 (2-3), pp. 172-194. DOI: 10.1016/j.lrp.2009.07.003.

[71] Tiwana, A., Konsynski, B., \& Bush, A. A. (2010). Research commentary-Platform evolution: Coevolution of platform architecture, governance, and environmental dynamics. IS Research.

[72] Timmers, P. (1998). Business models for electronic markets. Electronic markets, 8(2), 3-8.

[73] Tranfield, D., Denyer, D., \& Smart, P. (2003). Towards a methodology for developing evidence-informed management knowledge by means of systematic review.

[74] Turber, S., Vom Brocke, J., Gassmann, O., \& Fleisch, E. (2014). Designing business models in the era of internet of things. In International Conference on Design Science Research in Information Systems (pp. 17-31). Springer.

[75] Uckelmann, D., Harrison, M., \& Michahelles, F. (2011). An architectural approach towards the future internet of things. In Architecting the internet of things,Springer, Berlin.

[76] Vargo, S.L., Lusch, R.F. (2007): Service-dominant logic: continuing the evolution. J. Acad.

[77] Vermesan, O., Bahr, R.,Gluhak, A., Boesenberg, F., Hoeer, A., Osella, M. (2016). Unify-IoT.

[78] Vermesan, O., \& Friess, P. (Eds.). (2013). Internet of things: converging technologies for smart environments and integrated ecosystems. River Publishers.

[79] Veit, D., Clemons, E., Benlian, A., Buxmann, P., Hess, T., Kundisch, D., ... \& Spann, M. (2014). Business models. Business \& Information Systems Engineering, 6(1), 45-53.
[80] Vom Brocke, J., Simons, A., Riemer, K., Niehaves, B., Plattfaut, R., \& Cleven, A. (2015). Standing on the Shoulders of Giants: Challenges and Recommendations of Literature Search in Information Systems Research. CAIS, 37, 9.

[81] Wirtz, B. W., Pistoia, A., Ullrich, S., \& Göttel, V. (2016). Business models: Origin, development and future research perspectives. Long range planning, 49(1), 36-54.

[82] Whitmore, Andrew; Agarwal, Anurag; Da Xu, Li (2015): The Internet of Things-A survey of topics and trends. In Inf Syst Front 17 (2), pp. 261-274.

[83] Webster, Jane, and Richard T. Watson. (2002) Analyzing the past to prepare for the future: Writing a literature review. MIS quarterly (2002): xiii-xxiii.

[84] Westerlund, M., Rajala, R., Leminen, S.(2011). Insights into the dynamics of business models in the media industry, 42 p. Laurea Publications A74, Vantaa.

[85] Westerlund, M.; Leminen, S.; Rajahonka, M. (2014): Designing BMs for the Internet of Things, Technology Innovation Management Review, July, pp. 5-14.

[86] Weinberger, M., Bilgeri, D., \& Fleisch, E. (2016). IoT business models in an industrial context. atAutomatisierungstechnik, 64(9), 699-706.

[87] Weiller, C., \& Neely, A. (2013). Business model design in an ecosystem context. University of Cambridge, Cambridge Service Alliance.

[88] Wurster, L. F. (2014). Emerging Technology Analysis: Software Licensing and Entitlement Management Is the Key to Monetizing the Internet of Things (Vol. 251790). Gartner [89] Yip, G. (2004). Using strategy to change your business model.

[90] Yoo, Y. (2010) Computing in everyday life: A call for research on experiential computing. MIS.

[91] Zott, C., Amit, R., \& Massa, L. (2011). The business model: recent developments and future research. Journal of management, 37(4), 1019-1042.

[92] Zott, C., \& Amit, R. (2010). Business model design: an activity system perspective. Long range planning, 43(2-3).

[93] Zott, C., \& Amit, R. (2007). Business model design and the performance of entrepreneurial firm. 